\title{
A efetividade do sistema único de saúde brasileiro como garantia de direitos humanos no neoconstitucionalismo
}

The effectiveness of the unique Brazilian health system as a guarantee of human rights in the neoconstitucionalism

lago de Souza Marconi

Centro Universitário de Bauru (CEUB) - Instituição Toledo de Ensino (ITE)

iago.souza.m@hotmail.com

Luiz Nunes Pegoraro

Centro Universitário de Bauru (CEUB) - Instituição Toledo de Ensino (ITE)

professor@pegoraros.com.br 
Diante do questionamento acerca de o que se fazer para garantir a efetividade dos direitos do cidadão constitucionalmente resguardados e impedir uma iminente crise do estado garantista, mormente no tocante ao direito à saúde e quanto ao Sistema Único de Saúde; com o método hipotético-dedutivo, bem como dialético e sob o viés metodológico do neoconstitucionalismo, o texto aborda a tríplice base do Direito (sociológica, filosófica e dogmática), além de buscar introduzir o Constitucionalismo cooperativo e o Estado de Coisas Inconstitucional como meio de efetivação do texto constitucional no romper da pós-modernidade. Os acontecimentos recentes da pandemia provocada pela covid-19 reforçam a ideia de que fluidez, a instantaneidade e a dinamicidade marcam os "novos tempos" e exigem do Judiciário uma postura ativa e dialógica. O marco da racionalidade faz-se presente como forma de promover a validade e a efetividade do direito à saúde previsto na Constituição Federal, sendo a filosofia usada como base para uma nova visão hermenêutica do Direito.

Palavras-chave: Direito à saúde; Neoconstitucionalismo; Racionalidade; Constitucionalismo cooperativo; Estado de Coisas Inconstitucional.

\section{Abstract}

Faced with the questioning of what to do to ensure the effectiveness of the rights of the citizen constitutionally protected and prevent an imminent crisis of the guarantor state, especially with regard to the right to health and the Unified Health System; with the hypothetical-deductive method, as well as dialectical and under the methodological bias of neoconstitutionalism, the text addresses the threefold of law (sociological, philosophical and dogmatic), besides seeking to introduce Constitutionalism and the Unconstitutional State of Affairs as a means of effectiveness of the constitutional text in the breaking of postmodernity. The recent events of the pandemic caused by covid-19 reinforce the idea that fluidity, instantaneity and dynamicity mark the "new times" and require the Judiciary an active and dialogical posture. The framework of rationality is present as a way to promote the validity and effectiveness of the right to health provided for in the Federal Constitution, and philosophy is used as a basis for a new hermeneutic view of law.

Keywords: Right to Health; Neoconstitutionalism; Rationality; Cooperative constitutionalism; State of Inconstitutional Affairs. 
Há muito tempo se observa a precariedade da prestação do direito à saúde no Estado Brasileiro. Todavia, nos tempos da pandemia causada pelo novo coronavírus, a área da saúde nunca teve tanto destaque e necessidade de atenção.

Pesquisas avançam para encontrar meios de controlar o quadro infeccioso e prestar efetivo atendimento aos contaminados. É neste ínterim que a saúde pública e o SUS são expostos de forma nunca antes vista, já que a superlotação de leitos e precariedade habitual na prestação de tal direito são levadas ao extremo. É dever do Estado e direito subjetivo do cidadão ter a vida garantida por meio de um Sistema Único de Saúde eficiente.

O direito social à saúde deve ser analisado na vigência da modernidade, sob o prisma dos marcantes acontecimentos nas vertentes sociológica, filosófica e jurídica, de modo que a atualidade possa promover meios de efetivar a prestação estatal da própria vida do cidadão.

Desta forma, os olhares se voltam para o seio social, o qual é inegavelmente afetado por fatores como a Modernidade Líquida, o Neoconstitucionalismo e a problemática da racionalidade. Por meio do método hipotético-dedutivo, assim como sob o ponto de vista dialético, a presente pesquisa pretende demonstrar e explicar os fatores modernos que contribuem para uma visão completa acerca da efetividade dos direitos fundamentais, especialmente o direito à saúde.

O que se pode a priori observar é que com a Modernidade líquida, os paradigmas nos quais a sociedade era fundada passaram a ser remodelados e a segurança para a condução de tal modulação coube ao
Direito, mais especificamente ao ordenamento jurídico com destaque para a Constituição Federal. A inclusão de normas de maior abstração e conteúdo principiológico com correspondência na Moral e na Ética passou a desmistificar o entendimento acerca da efetividade de princípios constitucionais, como o da proteção à saúde. Essa construção gradual e possível retorno a pilares encontrados analogicamente no iusnaturalismo caracterizam o chamado neoconstitucionalismo.

Por fim, tendo como pano de fundo a reconstrução do arcabouço principiológico social e sua recondução ao mais alto paradigma do ordenamento jurídico, as normas de alto caráter axiológico passaram a ser questionadas quanto à possibilidade de sua efetividade enquanto mero norte para o Estado Democrático de Direito. O citado questionamento é então explicado pela questão da racionalidade encontrada na Teoria do Agir Comunicativo, e complementada pela visão da Argumentação Jurídica no Discurso Racional. $\mathrm{O}$ binômio validade $\mathrm{x}$ efetividade é realçado nas entrelinhas de temas como a reserva do possível e a separação de "poderes", culminando na proposição de medidas pouco convencionais para sanar a inércia estatal na prestação do direito à saúde no plano do Estado Brasileiro.

Diante da falha na efetivação do serviço do Sistema Único de Saúde (SUS) durante a pandemia provocada pelo novo coronavírus, o trabalho apresenta duas propostas de intervenção: (I) 0 constitucionalismo cooperativo, como forma de reforçar o diálogo institucional entre os entes da Federação; o que 
inclusive tem sido observado com resultados positivos; e (III) em último caso, a interferência do Poder Judiciário com a aplicação da técnica do Estado de Coisas Inconstitucional.

\subsection{Constitucionalismo Moderno}

O século $X X I$ é marcado principalmente pelo amadurecimento das teorias constitucionais iniciadas no séc. $\mathrm{XX}$, como a evolução do Estado Social, por exemplo. Diversos fatores são invocados para explicar a produção jurídica e a (re)estruturação social nos últimos anos, mormente no Brasil, cuja forma de um Estado Democrático de Direito possibilita a ampla proteção de Direitos Humanos de seus cidadãos e um crescente diálogo com a sociedade rumo à evolução de seus conceitos.

Alguns pontos merecem destaque no quadro fático. A fim de alinhar a análise à característica tríplice do Direito, o mesmo será feito com os fatores a serem evidenciados, de modo que ao debruçarse sobre um amplo espectro humano (sociológico, dogmático/jurídico) filosófico

complementação haja da constitucionalista moderna.

Do ponto de vista sociológico, ganha destaque a teoria da "modernidade líquida" do sociólogo polonês Zygmunt Bauman. Um trecho que funciona como chave para entender o pensamento do sociólogo neste corrimão é o seguinte:

\footnotetext{
'Derreter os sólidos' significava, antes e acima de tudo, eliminar as obrigações 'irrelevantes' que impediam a via do cálculo racional dos efeitos; como dizia Max Weber, libertar a empresa de negócios dos grilhões dos deveres para com a família e o lar e da densa trama das
}

obrigações éticas; (Bauman, 2000, p. 10)

Nesse caso, a família, o lar e o casamento são exemplos de paradigmas que foram "derretidos" (tornados líquidos) para serem "colocados em uma nova forma", para assim se formar a "nova ordem". Esses modelos estavam unidos, como foi citado, às obrigações éticas das pessoas e dessa forma, liquefazer esses conceitos resultou em uma realocação de valores e condutas de todos.

A sociedade quedou-se diante de um quadro de nova construção conceitual, em que o viés axiológico ganhou destaque não somente pela estruturação da sociedade, mas por sua quase imanente remodelação e os benefícios que a desconstrução de conceitos obsoletos poderia ocasionar aos integrantes de um grupo social. Obviamente a organização de conceitos modernos não ocorreu de forma desenfreada, caso contrário a insegurança conceitual seria tamanha que jamais se poderia falar em superação de paradigmas.

O diálogo da sociologia com a Ciência do Direito foi fundamental para a manutenção e evolução de conceitos básicos da sociedade inseridos a partir de uma nova mentalidade metodológica no tocante aos valores a guiarem um Estado. $O$ ordenamento jurídico passou então a guardar consigo o cerne básico, os alicerces da "nova sociedade". Tal proteção deu-se com a inclusão de normas (regras ou princípios) com cada 
vez mais conteúdo correspondente na Moral ou na Ética, todavia sem que houvesse a submissão do Direito aos axiomas morais.

A independência da Dogmática Jurídica foi preservada, não obstante ser impossível tratar o Direito como "pura" teoria distanciada dos conceitos valorativos ético-morais. $\mathrm{O}$ que se pode vislumbrar é uma colaboração harmônica com base na teoria positivista, em que pese não mais primária, que culmina no dever de tutela efetiva dos direitos por parte do Estado, ainda que tais direitos tenham por fim a salvaguarda de princípios de claro fundo moral.

Faz-se mister a esta altura destacar que o ramo do Direito de mais destaque para a teoria contemporânea é o Direito Constitucional, dada sua clássica relevância no quadro histórico para a defesa de direitos humanos e pelo denso conteúdo cultural advindo das constituições. Destaquem-se os ordenamentos que garantem maior proteção às constituições (rígidas), como o caso do Brasil.

Neste ponto, de análise do viés sociológico e da vertente jurídica, pode-se falar da teoria do "neoconstitucionalismo". A moderna teoria, que mais a frente será posta em diálogo com o chamado "Constitucionalismo Ético" traz consigo a análise de pontos harmônicos entre o iusnaturalismo e o positivismo jurídico, no tocante à inserção de conteúdos axiológicos na construção do Direito. Ressalte-se que:

O que aqui queremos demonstrar é que a concepção de direito iusnaturalista (ao menos sua parte principal) não se resume apenas à pergunta iuspositivista sobre como identificar o direito (what's the law?).

A concepção iusnaturalista abarca, também, essa interrogante, mas de maneira acessória. Todavia, sua questão principal se refere ao que deve conter o direito (What does the law requires?). Se tal perspectiva é correta, ao analisar a tese iusnaturalista devemos ter o cuidado de atentar para o fato de que esta teoria se propõe à resposta dessas duas interrogantes; e não apenas à primeira, como é o caso do do positivismo jurídico. Nesse caso, fica evidente a necessidade iusnaturalisa de condicionar o direito à moral. (Möller, 2011, p. 56)

Desta forma, a sujeição à moral não ocorre como forma de menosprezar o Direito, mas como forma de complementá-lo, haja vista que diversos conceitos jurídicos não podem ser definidos pela simples codificação.

Logicamente não há a pretensão de retornar a um jusnaturalismo, mas de observar sua construção, dialeticamente confrontá-lo com o positivismo e identificar os pontos que merecem complementação. Há muito a tese da Teoria Pura do Direito de Hans Kelsen mostrou-se insuficiente para a tutela integral dos direitos do Homem e do Cidadão, contudo, não se pode negar a influência que Kelsen exerceu sobre os critérios de identificação e estruturação do sistema jurídico como um todo, bem como o conteúdo do Direito em si.

O diálogo entre as teorias demonstra que a normatividade não é por si só uma causa de exclusão de qualquer conteúdo moral, por menor que seja. A modernidade, como analisado acima, demonstrou a necessidade de introduzir no ordenamento jurídico normas que visem a 
proteção do indivíduo como um todo, mas não somente de maneira a tratá-lo como receptáculo de direitos, como também o visando como cidadão, como sujeito integrante da sociedade, como ser cultural. O novo paradigma do cidadão faz com que a Constituição integre cada vez mais normas de conteúdo axiológico, seja pautado na Moral ou na Ética.

A respeito de tais normas com correspondência na Moral, é preciso ressaltar que:

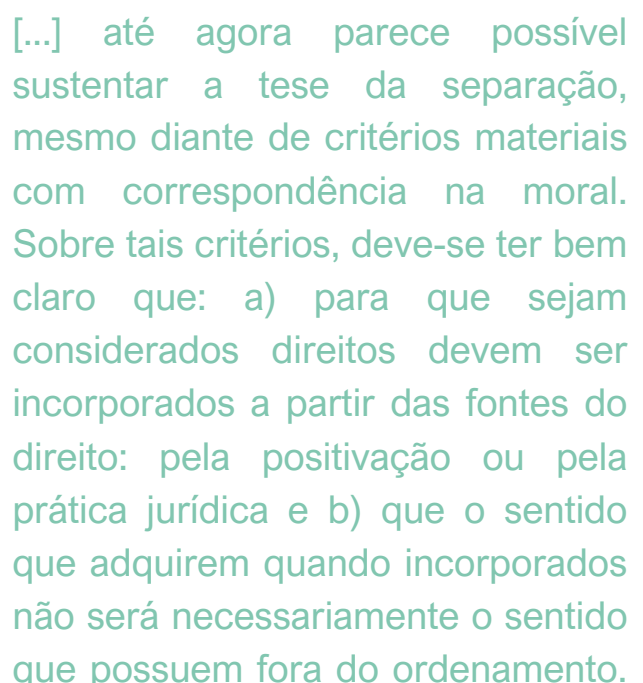

(Möller, 2011, p. 102)

Portanto, a inclusão no ordenamento constitucional de normas com correspondência na Moral não interferem na separação definitiva desta com o Direito. Ocorre que o atual quadro de interação Direito-Moral não pode ser negligenciado a ponto de se negar a influência de um em outro. A separação não impede a construção social conjunta e interações pontuais marcadas pela influência axiológica no conteúdo do Direito.

Mais do que a interação com a Moral, o neoconstitucionalismo propõe também uma nova metodologia quanto à efetividade das normas constitucionais. Com base neste viés constitucional integrador e dialógico, a Constituição deve ser entendida como um todo, de modo que regras e princípios sejam efetivados ainda que ligados a questões puramente axiológicas. A efetividade das normas constitucionais não deve ficar adstrita a um entendimento clássico a determinada estrutura normativa que direcione ao legislador ordinário um fazer, por exemplo.

Logo, a chamada reserva do possível é entendida como adequação do princípio à realidade fática quanto ao que está disponível para ação, mas não como uma barreira que sustente inabalavelmente um quadro massivo de violações de direitos humanos dos cidadãos. Aceitar um estado de coisas que viola sistematicamente os direitos de seus integrantes é destituir todo o discurso prático do texto constitucional.

Logo, diante da modernidade líquida e da congruência com o neoconstitucionalismo, surge a necessidade de voltar-se para a questão filosófica, de modo que a teoria seja integralmente observada a embasar a evolução dos direitos ao longo do tempo. A fim de abordar completamente a questão da efetividade dos direitos fundamentais e do Sistema Único de Saúde, é preciso entender a questão da racionalidade, vetor que influencia a validade e eficácia das normas jurídicas.

\subsection{A problemática da racionalidade}

A questão da efetividade envolve antes um discurso acerca da validade da norma. Para que se analise a validade de uma norma constitucional, seu valor racional deve ser previamente compreendido. É sabido para a teoria do Direito que para uma norma ser eficaz, isto é, para que esteja apta a produzir os efeitos a que foi criada, é necessário antes que ela seja válida. Para a visão moderna acerca da validade, esta está atrelada ao conceito de 
racionalidade, pois "[...] quanto melhor se puder fundamentar a pretensão de eficiência ou de verdade proposicional associada a elas, tanto mais racionais elas serão" (Habermas, 2012, p. 34).

O filósofo Jürgen Habermas descreve em sua Teoria do Agir Comunicativo (2012) a questão da racionalidade na teoria do discurso enquanto integrador da ação humana em sociedade. A racionalidade surge como um elemento da comunicação que, no discurso regulamentador, ou seja, normativo/imperativo, rege as relações de validade da norma. Alguns autores, como Robert Alexy criticam a forma como Habermas identifica a ação regulativa, sendo que as normas jurídicas acabam por ter a mesma classificação que as promessas, por exemplo, todavia, aprofundar o tema neste ponto não é essencial para a presente pesquisa.

O que se deve destacar acerca do agir regulamentado por normas é que a racionalidade se mostra pela "pretensão de correção", isto é, que a racionalidade da norma e sua consequente aceitabilidade do discurso está atrelada à validade da norma, pois a correção corresponde à inserção da norma no sistema jurídico e a possibilidade de intervir no plano fático, produzindo efeitos.

Conforme visto, a racionalidade está diretamente ligada à questão da pretensão de validade, seja esta sob o prisma da "inteligibilidade/eficácia", da "verdade", da "correção" ou da "veracidade", a depender o tipo de "ato de fala" emitido (imperativo, constatativo, regulativo ou expressivo, respectivamente). Para nós, importa o que Habermas chama de ato de fala regulativo e sua pretensão de validade ligada à correção. Logo, a racionalidade da norma está associada à verdade de sua pretensão à correção, ademais, a pretensão de validade dos atos de fala na teoria da verdade do citado autor relaciona-se à fundamentabilidade de seu discurso.

Antes de prosseguir, faz-se mister apresentar uma série de esclarecimentos a respeito da Teoria do Agir Comunicativo. Em primeiro lugar, há que se deixar evidente que para Habermas e sua teoria, a verdade é obtida por meio do consenso, sendo esse um produto obtido somente por meio da comunicação. A verdade consensual ampara o entendimento de que a racionalidade encontra-se pela atuação da sociedade. Conforme destaca Marcaro (2010, p. 361), "[...] a verdade se constrói enquanto processo comunicacional. Habermas afasta, assim, o idealismo e mesmo o empirismo estreito de sua filosofia. O nível de interação comunicacional passa a ser o fundamento da própria construção social".

Para chegar ao consenso como fundamento da Verdade, o filósofo parte de uma análise sobre a racionalização da sociedade, a qual por meio de processos de entendimento (o que não se pode confundir com a aprendizagem), desmistifica as formas "mágicas" que antes norteavam a ação da sociedade e racionalmente chega a um consenso produzido de maneira democrática, isto é, envolvendo a vontade geral, salvo as situações de equívoco que poderiam ocorrer, como ancorar uma ideia de verdade sobre um conceito equivocado.

Portanto, de modo a sintetizar o entendimento Habermasiano e sua importância para a efetividade de uma norma jurídica, entende-se que para uma norma constitucional ser efetivada, deve ser esta amparada pela validade (correção 
com o sistema) e desenvolver consequentemente um espectro de racionalidade, de modo que o discurso gerado entre a norma e o sistema, bem como entre o Estado cumpridor da norma e o indivíduo, produza efeitos concretos no plano fático, alterando a percepção da norma pela filosofia e a verdade das proposições decorrentes de sua aceitação no plano jurídico por meio dos consensos comunicativos.

Ocorre que atrelar a racionalidade de uma norma à verdade obtida por um consenso traz prejuízos à compreensão do Direito em si. Um grande questionador dessa alocação da verdade no consenso é Robert Alexy. $\mathrm{O}$ autor inicialmente destaca que:

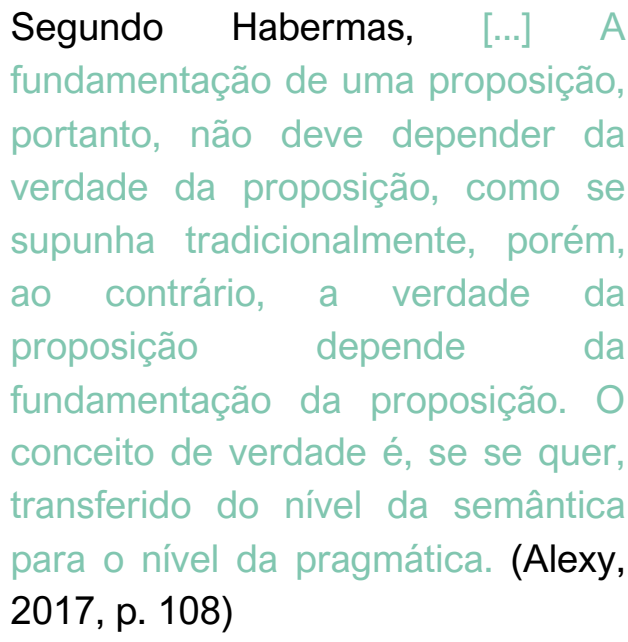

Diante deste quadro, resta evidente que a verdade fundamentada no consenso propõe a inversão da clássica compreensão que conduzia a uma segurança ao menos imediata a respeito dos metaprincípios, por exemplo, tendo em vista que uma "classe" elevada de direitos e princípios postos no seio constitucional estariam ligados à Verdade atemporal e axiológica da sociedade, remetendo 0 entendimento ao contemporâneo "neoconstitucionalismo", sem perder, contudo, a característica positivista do Direito.
A discussão acerca da verdade consensual e não como correspondência, a priori realoca o eixo do pensamento empírico para o pensamento racional; ainda que Habermas coloque a pragmática discursiva no âmbito da prática racional, o "empirismo" do consenso apresentado no estado de coisas advém do exercício da racionalidade no plano interno de cada indivíduo integrador do discurso. Tal colocação expõe a chamada "situação ideal de fala" com as "razões" do discurso e suas regras de fundamentação, sendo que atender a todas elas na teoria habermasiana queda-se praticamente inobservável:

\section{Segundo a teoria consensual, acordo potencial de todos é a condição tanto para a verdade de uma proposição não normativa quanto para a correção de uma proposição normativa. Esse critério de verdade tem duas deficiências: por um lado, não pode ser cumprido e, por outro, mesmo cumprido não seria suficiente. [...] Habermas tenta enfrentar essas dificuldades em seus ensaios sobre as teorias da verdade, estipulando que somente um consenso fundado (ou fundamentado) serve como critério de verdade. (Alexy, 2017, p. 114).}

Por fim, conclui-se que a racionalidade, em que pese a base na verdade consensual, apresenta-se como um meio adequado para verificação de validade e pretensão de efetividade de uma norma no caso concreto. Alinhado à visão do neoconstitucionalismo, a racionalidade é expressão de força dos direitos fundamentais e normas principiológicas. $\mathrm{O}$ que se pode adequar, segundo as críticas de Alexy, é alinhar a classificação dos atos de fala, mas ainda mais importante, 
adequar o referencial de Verdade para a correspondência, de modo que o parâmetro de validade e efetividade dos princípios constitucionais estejam ligadas aos axiomas que, norteando a sociedade na modernidade líquida, garantem a evolução dos conceitos e garantia de direitos de forma segura.

\section{O Direito à Súde como Direito Humano}

O Direito à saúde vem previsto na Constituição Federal (CF/88) especialmente nos artigos 196 a 200, em que se evidencia ser "um direito de todos e dever do Estado". Na Constituição Brasileira, o direito à saúde pode ser classificado como um direito social e como tal, possui congruência com o "status" de Direito Humano.

Os direitos sociais representam a evolução do Estado por serem caracterizados como direitos de segunda dimensão, ou seja, uma geração de direitos conquistados tendo por escopo a prestação positiva do Poder Público caracterizada pela efetivação da igualdade dos cidadãos. A igualdade, para além da isonomia, visa reconhecer em todo sujeito a dignidade da pessoa humana e como tal promover ao indivíduo o mínimo existencial para que conviva em sociedade.

Para elucidar a importância dos direitos sociais, "Vale lembrar, nessa linha de reflexão, que os direitos sociais, como os direitos fundamentais de segunda geração, são aqueles que reclamam do Estado um papel prestacional, de minoração das desigualdades sociais" (Araujo e Nunes, 2016, p. 277). Logo, são fundamentais para a existência digna do ser humano enquanto sujeito de direitos. Vale destacar que a Saúde é um dos fatores levados em consideração ao avaliar o Índice de Desenvolvimento Humano (IDH) de um país.
A Constituição elenca a saúde como direito social em seu art. $6^{\circ}$, destacando a importância e a necessidade de efetivação desse direito. Quando se observa o rol dos artigos 196 a 200 da CF/88, percebe-se que não é possível tratar do direito à saúde sem adentrar no mérito do Sistema Único de Saúde (SUS), porque é pelo SUS que o Estado Brasileiro presta o serviço público da saúde indistintamente aos cidadãos.

Não é mistério que diversas regiões contam com índices precários de qualidade e quantidade de atendimentos hospitalares, sendo que o quadro ganhou ainda mais destaque diante da pandemia de covid-19. O sobrecarregado e fragilizado Sistema de saúde viu-se obrigado a acolher, além da já quase invencível demanda no quadro atual, os diversos pacientes acometidos pela recente enfermidade.

O Direito à saúde, especialmente em um país de dimensões populacionais e territoriais extensas como o Brasil, traduzse no desafio de atender de forma igualitária e eficiente a população. O atendimento da saúde pelo SUS é norteado pelos princípios que o regem e, segundo Maingué $(2015$, p. 273):

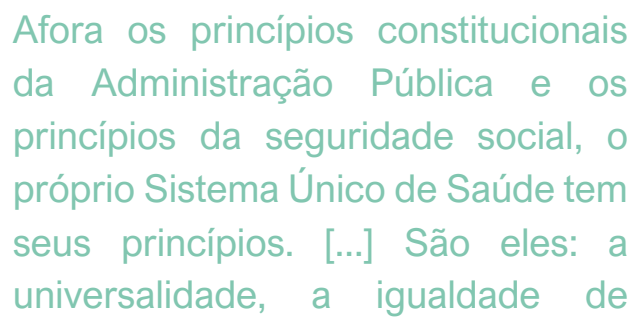
da Administração Pública e os princípios da seguridade social, o próprio Sistema Único de Saúde tem universalidade, a igualdade de 
acesso, a gratuidade, a integralidade da assistência, o federativo, o democrático e a legalidade.

Conforme visto, os princípios a regerem o SUS são expressão primária de sua concretização. Por serem princípios constitucionais advindos de um Direito Fundamental Social (e Humano), tais princípios devem ser integralmente observados e efetivados, sob pena de afronta à eficácia a priori de tais normas, como visto acima. Cabe ao Legislador e ao Executivo a elaboração de políticas públicas que tenham como foco a garantia da prestação integral da saúde por meio do SUS, especialmente pelo princípio da integralidade da assistência.

Uma assistência integral é efetivada quando o sujeito acometido por uma enfermidade precisa do Sistema Único de Saúde e encontra além de facilidade de acesso, um atendimento digno, célere, eficiente e de qualidade. desatendimento desse princípio importantíssimo para a compreensão do papel do SUS na prestação do direito à saúde é um flagrante desrespeito aos direitos subjetivos do cidadão de terem sua integridade física resguardada.

Logicamente, o Estado não tem condições de arcar com os mais caros tratamentos a todos os indivíduos, porém, a reserva do possível não pode ser entendida como cláusula limitadora do exercício de um direito. Deve o Estado se organizar de modo a alocar receitas, mesmo que com caráter provisório e emergencial, na tentativa de melhorar o quadro de atendimento médico-hospitalar da comunidade.

A realização de mutirões ou mesmo os hospitais de campanha para tratamento de pacientes com covid-19 são exemplos de medidas tomadas para garantir a integralidade da assistência à saúde de todos os afetados pela pandemia. É por meio de políticas públicas eficientes que o Estado promove a tutela integral dos princípios constitucionais ligados à saúde, principalmente os relacionados ao Sistema Único de Saúde, uma estrutura sem precedentes a nível mundial e que carece de atenção orçamentária, logística e até mesmo política por parte das Funções da República.

Admitir a não prestação desse direito é caracterizar uma inércia sistêmica e atentatória à Constituição Federal, pois "A admissão de tal impossibilidade material de cumprimento de um direito fundamental deve ser tida como uma exceção, que não se presume, sendo que cabe ao Poder Público [...] a demonstração da impossibilidade fática" (Rothenburg, 2014, p. 83).

\section{Instrumentos de Efetividade}

Portanto, constatada a importância e a necessidade de efetividade do Direito à Saúde por meio da concretização qualitativa e quantitativa do Sistema Único de Saúde (SUS), há que se apresentar meios para a formulação de políticas públicas eficientes voltadas à concretização de tão importante direito social.

Em primeiro lugar, há que se explorar a questão do Constitucionalismo Cooperativo como meio próprio dos entes federativos utilizarem-se de suas funções 
típicas, amparados na Constituição Federal, para efetivarem o Direito à Saúde por meio do SUS. A CF/88 já exemplifica o citado caminho quando prevê em seu art. 198, $\$ 1^{\circ}$, que "o sistema único de saúde será financiado, nos termos do art. 195, com recursos do orçamento da seguridade social, da União, dos Estados, do Distrito Federal e dos Municípios, além de outras fontes".

Além da alocação orçamentária, os entes federativos devem fazer uso de sua capacidade administrativa para organizar as estruturas de prestação de serviços em diversos níveis (municipal, estadual, federal e distrital). A técnica do Constitucionalismo cooperativo é justamente promover um diálogo institucional acerca da formulação de políticas públicas voltadas à superação de uma crise institucional, porém destaque-se que a iniciativa do diálogo parte das funções estatais típicas responsáveis pela formulação e implementação de políticas públicas, como o Executivo e o Legislativo.

O Constitucionalismo cooperativo é expressão do próprio princípio federativo do Sistema Único de Saúde, já que a prestação do serviço público se dá em coordenação com todos os entes da Federação, de modo a aproximar a máxima efetividade do cidadão, pois:

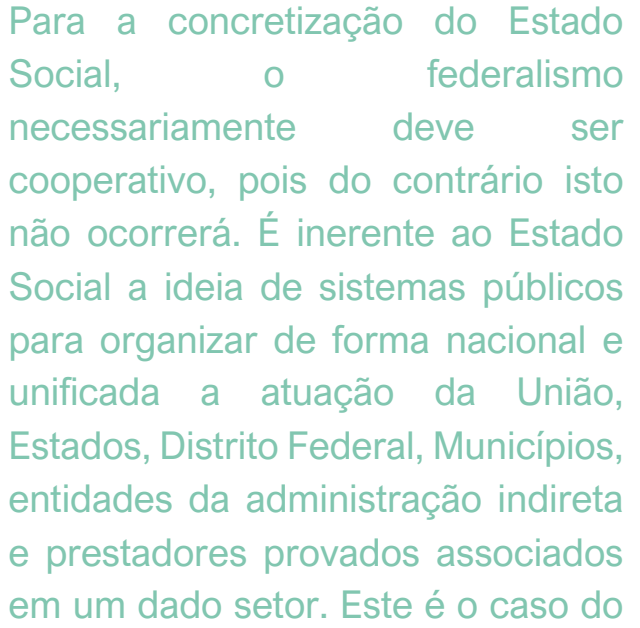

sistema único de saúde. (Maingué, 2015, p. 275)

Em último caso, na completa falha do Estado em exercer cooperativamente o federalismo, cabe ao poder não inerte agir de modo a efetivar a prestação da saúde por meio do Sistema Único de Saúde. A ação destacada pode ser encontrada na forma do Estado de Coisas Inconstitucional.

\subsection{O Estado de Coisas Insconstitucional}

A omissão estatal na prestação do disposto na Constituição Federal foi, por muito tempo, combatida apenas por meio de ações específicas como Ação Direta de Inconstitucionalidade por Omissão ou, em certos casos, Ação de Descumprimento de Preceito Fundamental.

Tradicionalmente, a omissão do legislador era "remediada" pela Ação Direta de Inconstitucionalidade por Omissão quando se tratava de normas que a doutrina dizia que a Constituição ordenava ao legislador ordinário uma ação no sentido de regulamentar determinado assunto. José Afonso da Silva (1982, p. 91) as chamava de "normas de eficácia limitada", isto é, aquelas que têm "aplicabilidade indireta, mediata e reduzida, porque somente incidem totalmente sobre esses interesses, após uma normatividade ulterior que Ihes desenvolva a aplicabilidade".

Portanto, dado o tradicional entendimento, as chamadas "normas de eficácia plena", isto é, aquelas previstas pelo constituinte originário sem que precisasse de ulterior edição simplesmente não tinham ferramenta que as fizesse eficientes, posto que o "dever-ser" positivista a sustentar o entendimento doutrinário de então era no sentido de que os Poderes seriam capazes 
de cumprir o disposto no seio constitucional como uma realidade imanente da própria função estatal.

Ocorre que, com o advento da (pós) modernidade e sob o viés de um constitucionalismo contemporâneo, temse a constatação de que os princípios e regras constitucionais devem ser objetivamente tratados, de forma que a tutela estatal sobre eles seja completa, apta a evitar a ação deficiente do Estado na guarda ou prestação de direitos e garantias fundamentais propostos pela Constituição, mormente no tocante à dignidade da pessoa humana e os princípios democráticos de participação efetiva do cidadão na formulação de políticas públicas eficientes, como a boa administração do SUS enquanto garantidor do direito à vida.

Inevitavelmente, o Estado falha na efetivação dos enunciados constitucionais. Tal falha não deve nunca ter como plano de fundo uma crítica à variedade de assuntos e normas tratados pela Constituição, sob pena de estarmos invertendo o espectro lógico que, em vez de buscar soluções para o plano fático, voltar contra o que tenta tutelar os direitos do indivíduo; seria uma culpabilidade completamente invertida, sob pena de perdermos toda a segurança sustentada pelo Direito. A respeito de tais falhas, cumpre destacar que:

Essas falhas revestem-se, via de regra, como deficiência dos ciclos de formação e execução de políticas públicas. Graves e sistemáticas violações de direitos são originadas e agravadas por falhas estruturais nos procedimentos de desenho, implementação, avaliação e financiamento de políticas públicas. Essas falhas têm raízes em prolongadas omissões dos agentes

e autoridades públicos, em limitações das políticas públicas correspondentes, na falta de medidas administrativas, legislativas ou orçamentárias voltadas a superação dos problemas de direitos. (Campos, 2016, p. 93).

De plano destaca-se que a omissão estatal não é momentânea, mas reiterada, fundada no não cumprimento dos enunciados constitucionais, tenha ele a natureza que tiver. Não se pode ater à espécie de norma, mas ao seu cumprimento. Faz-se mister destacar que não é somente a omissão que pode acarretar uma falha estrutural, isto é, de proporções tal que afetem toda a sociedade, mas a ineficiência de medidas tomadas pelos poderes também deve ser colocada em pauta. A proteção deficiente não é proteção. O quadro atual necessita de efetiva tutela dos direitos constitucional, semelhante à "lei do tudo ou nada" de Dworkin.

Diante da omissão ou ineficiência estatal, o povo, elemento integrante do Estado, fica desassistido e os enunciados constitucionais se tornam um epitáfio das políticas públicas. Assim, diante da inércia legislativa ou administrativa na formulação e implementação de políticas públicas, cabe ao Poder Judiciário tomar alguma atitude para que a Constituição seja efetivada em todos os seus aspectos.

É importante ressaltar que, em se tratando de um Estado Democrático de Direito tal qual o brasileiro, a existência de uma Corte Constitucional é essencial à concretização da prestação efetiva da tutela estatal. Portanto, diante da necessidade de agir, surge como instrumento o Estado de Coisas Inconstitucional, o qual pode ser definido, nas palavras de Carlos Alexandre 
de Azevedo Campos (2016, p. 185), como "uma ferramenta processual pela qual cortes produzem uma norma declaratória da contradição insuportável entre texto constitucional e realidade social".

É possível constatar, portanto, que o produto da jurisprudência da Corte Constitucional Colombiana trata-se não somente de um instituto material, este entendido como o quadro no qual se observam os pressupostos de aplicação da técnica, mas processual, visando a superação da inércia ou ineficiência estatal na prestação de um direito constitucionalmente assegurado. Deve-se ressaltar também que a declaração do Estado de Coisas Inconstitucional não é uma ação própria, mas esbarra, em todos os casos já observados, em ações ordinárias previstas pelo constituinte ou pelo legislador.

A definição parte da análise dos requisitos que, segundo Carlos Alexandre de Azevedo Campos, são (II) um quadro de violação massiva e contínua de diferentes direitos fundamentais, que afeta um número amplo de pessoas (2016, p. 180); (II) a omissão reiterada e persistente das autoridades públicas no cumprimento de suas obrigações de defesa e promoção dos direitos fundamentais (2016, p. 181); (IIII) a superação dos problemas de violação de direitos exigir a expedição de remédios e ordens dirigidas não apenas a um órgão, mas a um conjunto desses (2016, p. 183); e (IV) potencialidade de um número elevado de afetados transformarem a violação de direitos em demandas judiciais, que se somariam às já existentes, produzindo grave congestionamento da máquina judiciária (2016, p. 185).

A violação deve ser tal que atinja um número expressivo de lesados, de modo que o Estado tenha falhado em sua prestação efetiva de direitos ou garantias constitucionais. A violação, como já expressado, pode partir de uma omissão ou da ineficiência de medidas tomadas até então pelos Poderes públicos.

A omissão, ou ineficiência, por sua vez, deve ser persistente, ou seja, manter-se ao longo do tempo violando os direitos dos indivíduos e deve partir da falha no dever previsto pelo texto constitucional.

O terceiro pressuposto diz respeito à necessidade das chamadas "sentenças estruturais", isto é, aquelas que promovem ao Judiciário a legitimidade para agir como coordenador de diálogos institucionais nas diversas esferas e poderes do Estado. A superação é sistemática, ou seja, se apenas um órgão estivesse ocasionando a violação, bastaria o acesso simples à via jurisdicional que sanaria o feito como o faz regularmente. A declaração do Estado de Coisas Inconstitucional necessita de uma injunção que atinja diversos órgãos ou áreas do Poder Público, a denotar a ineficácia geral do Estado que só tem como válvula de escape a solução por meio de um órgão não inerte e legítimo, a Corte Constitucional.

Por fim, o acionamento da máquina judiciária por todos os lesados paralisaria ou interferiria drasticamente no correto funcionamento da jurisdição. Paradoxalmente, se os lesados recorressem todos ao Judiciário, a demanda seria tal que feriria o disposto no art. $5^{\circ}$, inciso LXXVIII, da Constituição Federal. É necessário tecer um comentário neste ponto no que diz respeito ao acesso ao Judiciário no Brasil: o Supremo Tribunal Federal tem naturalmente entraves ao acesso comum dos jurisdicionados, visando justamente evitar a superlotação do Tribunal, entretanto, a violação neste 
caso seria tal que a via ordinária seria altamente demandada e, por ser matéria constitucional, inevitavelmente teria seu curso, ainda que não na totalidade, endereçado ao STF, dificultando a atividade jurisdicional dos demais interessados.

De maneira sucinta, dada a síntese necessária ao presente trabalho, foram abordados os pressupostos para a declaração do Estado de Coisas Inconstitucional. A presença destes é imprescindível à declaração, sob pena de haver um protagonismo judicial desnecessário, ferindo assim o sistema de freios e contrapesos e a harmonia necessária entre os Poderes, consagrada no art. $2^{\circ}$, da CF/88.

A evolução do estudo para a conclusão de tais pressupostos foi desenvolvida a partir do estudo da jurisprudência da Corte Constitucional Colombiana, mormente no caso do deslocamento forçado, que culminou na "Sentencia T-024", marco decisivo para a estruturação e pleno desenvolvimento do Estado de Coisas Inconstitucional.

Há que se ressaltar também a separação das fases da aplicação do Estado de Coisas Inconstitucional, primorosamente explicadas por Juliana Patricio da Paixão sob a metáfora da árvore:

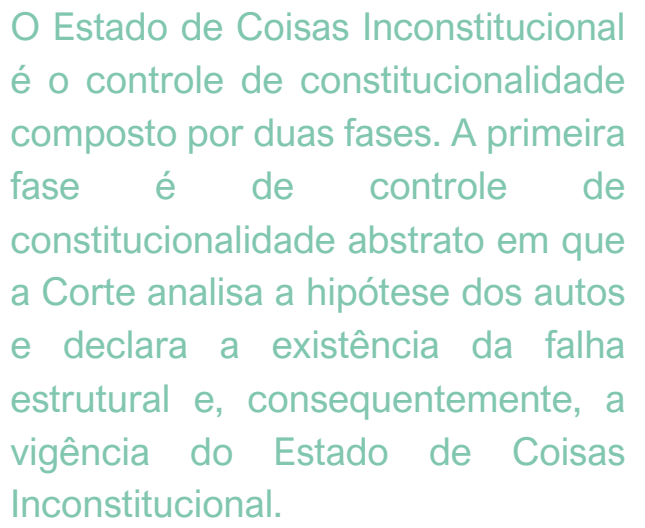

A segunda fase é composta pelo monitoramento de diretrizes estabelecidas na sentença estrutural. Dessa forma, consolida o controle de constitucionalidade concreto coletivo e individual na medida em que examina a realidade fática e indica a solução constitucionalmente adequada para a violação de direitos fundamentais. (2017, p. 93)

A observação dos pressupostos é necessária também para que haja segurança na atuação do Poder Judiciário enquanto protagonizado pela Corte Constitucional. A movimentação da máquina pública por meio de sentenças estruturais para resolver um problema que não se encaixe no caso de declaração do $\mathrm{ECl}$ seria excessivamente oneroso para o Estado e para a sociedade como um todo, já que chamada a colaborar efetivamente na superação desse quadro de violação massiva dos direitos.

Após a constatação da necessidade de declaração do Estado de Coisas Inconstitucional, cabe à Corte a estruturação de medidas que vão culminar na superação da violação ampla e massiva. O Poder Judiciário age como coordenador dos demais Poderes do Estado e órgãos correlacionados para trabalhar no fim da agressão (in)constitucional. Neste ponto surge a legitimidade do Poder Judiciário, diante de um "ativismo judicial dialógico", para suprir a falha ocasionada por todos os demais setores estatais. De fato, se Legislativo e Executivo não trabalham para o efetivo cumprimento do teor constitucional, é dever do Poder Judiciário fazer valer o enunciado da Lei Maior. 
Diante de todo o exposto, insta concluir que os princípios constitucionais ligados ao Sistema Único de Saúde devem ser integralmente cumpridos, levando-se em conta o quadro moderno que perpassa todo o ordenamento jurídico, este caracterizado pelo neoconstitucionalismo e amparado pela questão da racionalidade das normas constitucionais a garantirem a efetividade do texto Constitucional.

A sociedade enfrenta os efeitos da Modernidade Líquida, em que a remodelação de paradigmas afeta o âmbito jurídico com a inclusão de princípios baseados em axiomas morais. Essa carga principiológica incrustada principalmente no seio constitucional traz consequências como a maior proximidade, em que pese a independência, do Direito com a Ética e a Moral, o que repercute no modo como enxergar as normas constitucionais.

Os princípios demandam tanta efetividade quanto as regras, despontando uma visão neoconstitucionalista. No ramo da saúde pública e o direito humano a esta, o Estado passa a ser visto mais do que nunca como sujeito de dever inderrogável de prestar à população um serviço eficaz quantitativa e qualitativamente por meio do Sistema Único de Saúde. Os próprios axiomas do SUS devem ser enxergados não somente como balizadores da ação de seus agentes, mas também como normas constitucionais aptas a interferirem no plano fático.

Para que a norma efetivamente saia do texto, isto é, da questão semântica, e adentre na pragmática por meio de políticas públicas, é necessário um novo entender a respeito de sua validade e eficácia. Uma visão mais apurada é alcançada com a utilização do discurso racional, isto é, voltando-se para a análise da racionalidade das normas enquanto integrantes do Discurso Jurídico. Teóricos como Habermas e Alexy complementam a visão tradicional da racionalidade e a teoria confirma a linha intelectiva e metodológica do neoconstitucionalismo, bem como são tangentes à Modernidade Líquida de Bauman.

Estabelecido o novo paradigma em relação à efetividade e pretensão de realização dos princípios, percebe-se que o direito humano à saúde carece de mais atenção, posto os princípios do Sistema Único de Saúde por vezes não são levados em conta na prestação do serviço, mesmo não tendo sido esgotada a reserva do possível.

Para que a falha na prestação dos serviços relacionados à saúde não se tornem um problema estatal estrutural e viole ainda outros direitos reflexos do cidadão, é preciso agir. A pandemia provocada pelo novo coronavírus surge como flagrante necessidade de ação por parte do Poder Público.

O resultado é o nascimento urgente de um diálogo institucional baseado na forma federalista de Estado, tendo como base o constitucionalismo cooperativo, promovendo a interação de diversos entes e instituições dos níveis da Federação (União, Estados, Distrito Federal e Municípios). Portanto, como medida primária e até o momento bem sucedida, a cooperação entre os entes federados parece ser a atuação mais aconselhada 
para a formulação de políticas públicas voltadas ao enfrentamento da crise sanitária.

Explorar as funções típicas dos Poderes do Estado é sempre a forma menos ruidosa e, como visto, mais proveitosa para os cidadãos, com a criação de hospitais de campanha, mutirões de testagem, acompanhamento de dados etc.

Se tais medidas não surtirem resultado e a falha na efetivação da Saúde pelo SUS se agravar, de modo a prejudicar também outros direitos humanos do cidadão, de forma sistemática e reiterada, pode-se cogitar a proposta de declaração do Estado de Coisas Inconstitucional (ECl) para que o Poder Judiciário, por meio de um ativismo judicial dialógico, possa agir como coordenador das demais funções ao realocar receitas e incentivar a implementação de políticas públicas, como foi no caso da ADPF 347/2015 sobre o sistema carcerário.

Ressalte-se que até o momento a prática do federalismo cooperativo tem demonstrado resultados satisfatórios, bem como a visibilidade de tais medidas provocam um efeito reflexo no princípio democrático do Sistema Único de Saúde ao mostrar para a população que é possível agir dentro da reserva do possível e prestar um bom serviço público. Por estes motivos, ao menos por enquanto, não é aconselhada a aplicação do $\mathrm{ECl}$, sendo esta condicionada à evolução da crise no Brasil. 

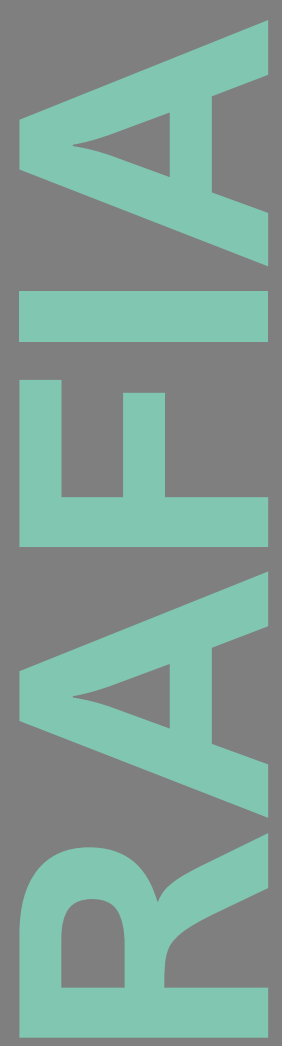

43
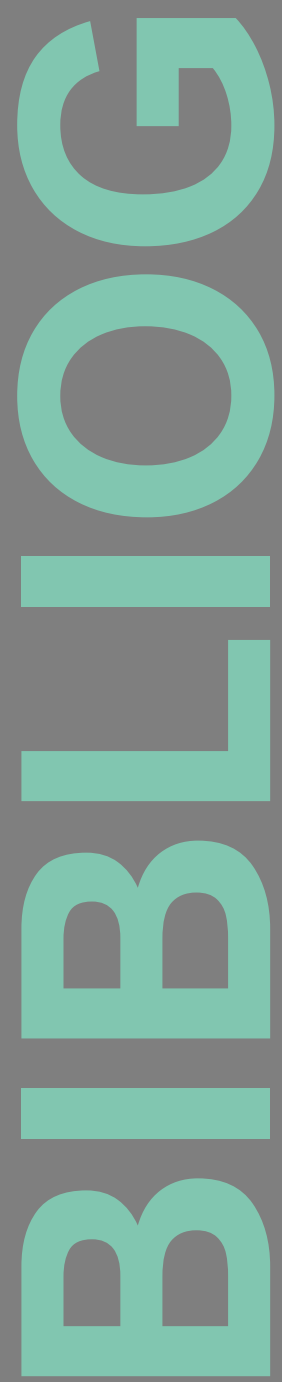

Alarcón, P. (2014). Ciência política, Estado e Direito Público: uma introdução ao Direito Público da Contemporaneidade. São Paulo: Verbatim.

Alexy, R. (2017). Teoria da Argumentação Jurídica. Tradução Zilda Hutchison Schild Silva. 4. ed. Rio de Janeiro: Forense.

Alexy, R. (2017). Teoria dos Direitos Fundamentais. Tradução Virgílio Afonso da Silva. 2. ed. São Paulo: Malheiros.

Andréa, G. (2018). Estado de Coisas Inconstitucional no Brasil. Rio de Janeiro: Lumen Juris.

Araujo, L. e Nunes Júnior, V. (2016). Curso de Direito Constitucional. 20. ed. São Paulo: Editora Verbatim.

Bauman, Z.(2000). Modernidade Líquida. Tradução de Plínio Dentzien. Rio de Janeiro: Jorge Zahar.

Cambi, E. (2009). Neoconstitucionalismo e neoprocessualismo: direitos fundamentais, políticas públicas e protagonismo judiciário. São Paulo: Revista dos Tribunais.

Campos, C. (2016). Estado de coisas inconstitucional. Salvador: JusPodivm.

Dallari, D. (2016). Elementos de Teoria Geral do Estado. 33. ed. São Paulo: Saraiva.

Di Pietro, M. (2019). Direito Administrativo. 32. ed. Rio de Janeiro: Forense.

Habermas, J. (2011) Direito e democracia: entre facticidade e validade. Vol. 1. Tradução Flávio Beno Siebeneichler. Rio de Janeiro: Tempo Brasileiro.

Habermas, J. (2011) O discurso filosófico da modernidade: doze lições. Tradução Luiz Sérgio Repa, Rodnei Nascimento. São Paulo: Martins Fontes.

Habermas, J. (2012) Teoria do Agir Comunicativo: racionalidade da ação e racionalização social. Vol. 1. Tradução de Paulo Astor Soethe. São Paulo: WMF Martins Fontes.

Kelsen, H. (1998). Teoria pura do Direito. Tradução João Baptista Machado. 6. ed. São Paulo: Martins Fontes.

Maingué, W. (2015). Efetivação do direito à assistência à saúde. São Paulo: Max Limonad.

Mascaro, A. (2010). Filosofia do Direito. São Paulo: Atlas.

Möller, M. (2011). Teoria Geral do Neoconsititucionalismo: bases teóricas do constitucionalismo contemporâneo. Porto Alegre: Livraria do Advogado. 
